\title{
Application and Analysis of Psychological Testing in Recruitment of
}

\section{Universities}

\author{
Zhongyu Zhou $^{1}$ \\ ${ }^{1}$ Department of Sociology, Chongqing University of Science and Technology \\ Chongqing, 401331 \\ 346591653@163.com
}

KEYWORDS: Psychological Testing, Recruitment of Universities, Standardized Psychological Tests

ABSTRACT: This article analyzes the psychological tests and objective investigation in Chongqing application status of college recruiting, recruiters and candidates as well as perceptions of psychological tests psychological tests Standardization. Recruitment for the College of correct understanding of the value of psychological tests, psychological testing of the implementation process of science and improve the effectiveness of university students in the selection of proposals.

\section{Introduction}

Teacher is known as the "engineers of human souls." Competency and moral quality of university teachers affect overall growth of healthy college students, thereby affecting the development of society and the State, therefore, crucial for the recruitment and selection of university teachers, research college recruiting program, recruitments tool for improving the recruitment of scientific meaning major.

Over the last decade psychological testing is widely used in recruitment, hiring one hand, it helps both parties fully understand the individual quality and value for the talent selection, recruitment and configured to provide important reference; on the other hand, a number of units and the lack of scientific testing agencies Applied Psychology sex, appears reliability and validity testing tools is not high, professional level testers and other issues is not enough, we have cause to question the psychological test. College recruiting is whether to apply psychological test eyes of the beholder, the wise see wisdom.

\section{Objective and Methods}

This paper studies the psychological test applications and the problems in Chongqing in college recruiting. According to the study purpose, the author uses literature analysis and in-depth interview methods were investigated and analyzed.

Through literature review, discussions with experts in the design of the survey questions, select the object 16 in-depth interviews, interview subjects covered Chongqing, 10 colleges and universities, including recruiters, psychological evaluation staff, candidates and ordinary teachers. (See Table 1)

Table 1 Statistics of interviewees 


\begin{tabular}{|c|c|c|c|c|c|}
\hline & Recruiters & $\begin{array}{c}\text { Psychological } \\
\text { Checkers }\end{array}$ & Applicants & $\begin{array}{c}\text { Ordinary } \\
\text { teacher }\end{array}$ & Total \\
\hline $\begin{array}{c}\text { Key } \\
\text { institutions } \\
(3)\end{array}$ & 1 & 1 & 1 & 1 & 4 \\
\hline $\begin{array}{c}\text { Ordinary } \\
\text { Institution } \\
(6)\end{array}$ & 3 & 1 & 2 & 3 & 9 \\
\hline $\begin{array}{c}\text { Military } \\
\text { College (1) }\end{array}$ & 1 & 1 & 1 & 0 & 3 \\
\hline Total & 5 & 3 & 4 & 4 & 16 \\
\hline
\end{tabular}

The survey includes the following questions: (1) the recruitment of teachers and school counselor procedures. (2) whether the application schools recruit psychological test, What test tools (3) understanding of the psychological tests, such as the need for the application of psychological testing in recruitment, psychological testing standardization issues. Jobs (4) evaluation of personnel, professional background, whether through professional psychological evaluation training?

Through statistical analysis of the results of the survey of college recruiting application status psychological test, and the person perception of psychological testing, standardized psychological tests carried out three aspects of thinking, and make recommendations.

\section{Results and Analysis}

Chongqing universities recruitment procedures are similar. Teacher recruitment procedures as follows: (1) resume screening (2) examination (3) interview (4) physical examination (5) contract. Resume screening, jointly completed by the Personnel and secondary schools Institute, the main reference candidate's qualifications and experience to select schools and colleges need to meet people. Interview assessment generally includes lecture and interviews in two parts, professionalism and overall ability to work in order to assess candidates. Such as interview assessment is passed, to the designated hospital for medical examination, those who pass the examination before signing.

Among them, a key university in Chongqing psychological tests, including written tests and structured interviews, written tests have EPQ, Holland vocational orientation and achievement motivation tests; structured interviews based on the title and the framework prepared in advance by the psychological experts one on one interviews understand the research and teaching in candidates, and the ability to make a comprehensive assessment based on their answers and psychological conditions. Taking into account the differences between the various expert score, each expert to make a score and ranking only in his interview several candidates in the.

Interviews with 10 colleges and universities in Chongqing 6 use of psychological tests, in addition to a military academy emphasizes confidentiality inconvenience inform scale testing tools, the remaining five universities in the recruitment scale has used SCL-90,16PF, Holland German vocational aptitude test, EPQ and achievement motivation test. More common to use mainly SCL-90 and 16PF and Holland vocational aptitude test, they are psychological evaluation of the candidate's degree of health and symptoms, personality traits and occupational interests and abilities expertise.

\section{Views on Psychological Testing}




\section{A. The Necessity of Psychological Testing.}

Teacher recruitment is necessary to do psychological testing reasons: First, teacher and mental health effects of student growth, many interviewees mentioned teachers now appear proportion of mental disorders, suicide, assault and other incidents rise in the recruitment phase should screen find such personnel, school teachers and students will minimize damage. The second is to improve teachers 'personality traits influence students' learning and personality, some teachers scientific research ability, but not well done the task of teaching, cannot get along with colleagues, unpopular among students. Third, some school leaders and troubled by the case, know the teachers and students suffer from psychological disorders is very difficult, will spend a lot of manpower and resources to handle the event, so to reduce potential risks in the recruitment phase, the test in advance to understand the psychological status of recruiters.

Job counselors think that the number of psychological tests should be done up to $100 \%$, of its reasons: First, we think that counselors working close to the students, their personalities will affect the overall situation of the students brought the class, the instructor can give as upbeat students deliver more positive energy; secondly, physical and mental health counselors will hurt students need to exclude security risks at the recruitment stage; third, counselors working for a long time, complicated affairs, mental stress, psychological need to recruit good quality who are able to do the job; fourth, counselor recruitment oversupply, do not worry about the psychological test causes the brain actively refused Universities.

\section{B. Recognition of Psychological Tests.}

In the 16 interviewees, $50 \%$ of people said that the recognition of psychological tests, psychological tests that the psychological barriers can filter out candidates, while the individual's ability to have a certain predictability. Especially as the candidate's interviewees have expressed do not exclude psychological test in recruitment, but not because of psychological tests and give candidates university work. Meanwhile, $18.75 \%$ of people are skeptical about the effectiveness of psychological tests, psychological tests that they need not join in college recruiting.

Table 2. The acceptance of psychological testing of college recruiting

\begin{tabular}{|c|c|c|}
\hline Options & Quantity & Percentage \\
\hline Approve & 8 & $50 \%$ \\
\hline Do not know & 5 & $31.25 \%$ \\
\hline Denied & 3 & $18.75 \%$ \\
\hline
\end{tabular}

\section{Standardized Psychological Tests}

Standardization refers to the preparation of psychological tests, implementation, test scores and scoring consistent interpretation of procedures, and have a high degree of reliability and validity and norm data. Standardized test is a systematic, scientific, standardized construction survey and assessment process, which includes the standardization of the whole process.

\section{A. Standardized Testing Tools.}

Various colleges and universities in the recruitment test tools used are more mature and extensive use of psychological scales internationally, which itself has a high reliability and validity. However, due to the completion of these scales longer, but also abroad, scale version, revision and translation levels will affect the Chinese version Science. Therefore directly affect the source testing tools standardized psychological tests. 
The survey found that colleges and universities are using psychological scales generally buy software company psychological test system (five colleges and universities) or borrow professionals have recommended psychological Scale Test Paper (1 College). Testing tools, mostly abroad, there are differences in Western culture and values, the scale needs to use through science amendment.

\section{B. Specialized Personnel Evaluation.}

College of Applied Psychology in six tests, five universities by the Counseling Center survey results school work department is a staff evaluation results; evaluation of staff five universities have psychology professional background, and for the country level counselors (secondary / tertiary), is a professional education background; evaluation of the case for training personnel, almost all personnel have participated in professional training in psychology, but did not participate in specialized psychological test personnel training.

Visible, universities involved in the recruitment of staff are mostly psychological evaluation counselors, teachers and psychology department staff recruitment. While the former is common sense understanding of psychology, not necessarily versed in psychological evaluation, interpretation of the results are often simple, most of them can identify whether the candidates have psychological problems, but explained with reference to the various dimensions of the test software, general evaluation, the lack of candidates personality and the ability to do further analysis. The latter generally have relevant professional background, learning directly through a simple induction, the test results cannot be accurate and comprehensive explanation.

\section{Conclusions and Recommendations}

To the public's knowledge of popular psychological tests, to change its recruiters for recruiters psychological testing prejudice through advocacy and training to understand the psychological test function in the college recruiting.

Psychological testing is through a series of measures, some of the psychological characteristics of the number of people to measure the level of individual psychological factors and individual psychological differences in a scientific measurement. Press the test content can be divided into 'psychological tests, personality tests and ability tests. Today, mental health and physical health are equally important, everyone should be treated like a physical examination as readily accept psychological examination - psychological tests. Recruiters do not prejudice the psychological test and the candidates do not have to avoid the psychological test. Establish the scientific knowledge of psychological testing, recruitment unit will no longer worry about the brain drain caused by the test.

Government agencies or industry associations should establish psychological testing regulatory authorities, the introduction of foreign scale strictly emphasized the revised scientific and localization, regulate all aspects of R \& D scale, before implementation is measured by professional certification; commonly used scale, according to their nature and content of the test, at intervals of years to organize experts to revise the scale, we can continue to use; the new scale developed to conduct scientific and objective assessment, the assessment can only be qualified to use. Mental software companies can only use professionally-accredited scale development of psychological testing products.

Because each situation is different colleges and universities, the lack of professional psychological testing some universities, inadequate staffing, limited professional resources, some universities have psychology, a huge contingent of professional teachers and rich psychological testing resources. Recommends the integration of resources, the ability of colleges and universities established psychological testing organizations to provide testing services to carry out recruitment 
testing other universities to hire a professional team in the form of outsourcing. This will not only solve the problem of inadequate staff in some schools, but also enhance the effectiveness of scientific and psychological tests, but also to ensure a fair and impartial assessment sectors.

\section{Acknowledgment}

Fund Project: Chongqing University of Science and Technology 2012 annual talent team construction project "the research of psychological test in college teachers recruitment application"

\section{REFERENCE:}

[1] Le National Security, and the application of ethics En boundary current psychological tests [J] Psychological Science, 2005,06: 16-18

[2] Morgeson F P, Campion M A, Dipboye R.L, et al.Reconsidering the use of personality tests in personnel selection contexts Personnel Psychology, 2007, 60, (3):. 683-729

[3] Linn, R.L.Measurement and Assessment in Teaching 8thed.NY:. Prentice-Hall, Inc., 2000: 17-18 